\title{
Propriedades Absorventes dos Produtos da Carbóxi- Metilação de Polpa Etanol/Água de Medula de Bagaço de Cana-de-Açucar
}

\author{
Cibele M. F. Martinez, Elisabete Frollini e Sérgio P. Campana Filho
}

Resumo: Polpas etanol/água de medula de bagaço de cana de açúcar foram empregadas para a obtenção de carbóxi-metil-celulose insolúvel, aplicável como material absorvente. Tipicamente, a reação de carbóximetilação da polpa branqueada foi realizada em suspensão de isopropanol/água $(1: 8 / \mathrm{m}: \mathrm{m})$ a $80{ }^{\circ} \mathrm{C}$ por 4 horas, empregando-se relação molar 1 / 5,4 / 8,8 de celulose / NaOH / ClAcOH. O material com melhores características corresponde a um produto muito pouco solúvel $\left(\mathrm{S}_{\mathrm{w}}<2 \%\right)$, com propriedades absorventes superiores às da polpa de partida.

Palavras-chave: Carbóxi-metil-celulose insolúvel; polpa etanol/água; medula de bagaço de cana de açúcar

\section{Introdução}

O bagaço de cana de açúcar representa a quarta produção mundial de fibras celulósicas para fins industriais, estimada em aproximadamente 4,1 trilhões de toneladas métricas anuais ${ }^{1}$. A moagem de cana para a produção de açúcar e álcool nas usinas brasileiras durante a safra 95 / 96 deve gerar cerca de 40 milhões de toneladas métricas de bagaço ${ }^{2}$, o que representa mais da metade da produção mundial.

O bagaço é intensivamente usado como combustível de caldeiras e, em menor escala, para a composição de ração animal e a preparação de polpas para manufatura de papel $^{3}$. Alguns estudos sugerem também outras utilizações potenciais tais como a produção de polpas químicas para a preparação de derivados de celulose ${ }^{4}$, a obtenção de termoplásticos ${ }^{5}$ e a preparação de compósitos ${ }^{6}$. Entretanto, as principais limitações ao emprego de polpas de bagaço se devem ao custo do transporte e à necessidade de se desenvolver e/ou adaptar as tecnologias apropriadas.

Quando o interesse focaliza a produção de polpas, a necessidade de etapas adicionais para a eliminação de impurezas e exclusão da medula, fração não-fibrosa correspondente a cerca de 30-35\% do bagaço integral, se constitui em mais um fator limitador do seu emprego.

Os teores de celulose, lignina e polioses presentes na medula e nas fibras são muito próximos entre si e àqueles de madeiras duras ${ }^{3}$. Entretanto, medula e fibras verdadeiras são diferentes do ponto de vista morfológico, quanto às suas funções fisiológicas e ao que diz respeito às respectivas capacidades de absorção de líquidos.

Em relação a essa última característica, uma aplicação potencial da medula pode ser antecipada na preparação de materiais absorventes. De fato, a 
demanda por materiais com elevada capacidade de retenção de água tem resultado no rápido crescimento da produção industrial de hidrogéis desde os meados da década de $80^{7}$.

A maioria dos absorventes, e principalmente dos superabsorventes, disponíveis no mercado é preparada a partir de polímeros sintéticos, essencialmente poliacrílicos ${ }^{7}$. Entretanto, estudos sobre a obtenção e caracterização de hidrogéis preparados a partir de polissacarídeos naturais vêm ganhando importância em vista das crescentes preocupações relacionadas com questões ambientais e também devido à abundância, disponibilidade e elevado grau de hidrofilicidade desses polímeros naturais ${ }^{8}$.

Outra possível vantagem dos hidrogéis baseados em polissacarídeos reside na elevada rigidez intrínseca de suas cadeias poliméricas quando comparadas a polímeros vinílicos ${ }^{9}$, disso resultando seu comportamento não-gaussiano ${ }^{10} \mathrm{e}$ melhores propriedades mecânicas ${ }^{8}$. Além disso, a presença de muitos grupos hidroxila oferece possibilidades de derivatização visando à melhoria das propriedades absorventes. Isso pode ser conseguido através da preparação de polissacarídeos polieletrólitos.

Polieletrólitos possuem elevada capacidade de inchamento em sistemas aquosos devido à presença, nesse tipo de gel, de cargas sobre a cadeia polimérica e dos respectivos contra-íons $\mathrm{H}^{+}$no meio líquido aprisionado no interior da rede. As interações eletrostáticas repulsivas entre as cargas sobre a cadeia e a pressão osmótica devido aos contra-íons $\mathrm{H}^{+}$se somam para aumentar o inchamento da rede ${ }^{11}$.

A carbóxi-metilação de celulose nas condições adequadas $^{12}$ ou a aplicação de procedimentos de purificação, tais como lavagens com misturas apropriadas solvente / não-solvente ${ }^{13}$, resultam em carbóxi-metil-celuloses substancialmente insolúveis dotadas de características absorventes muitas vezes superiores às das polpas empregadas como matériaprima. No sentido de avaliar o potencial do bagaço de cana de açúcar para a preparação de materiais absorventes, o presente estudo relata o emprego de medula como matéria-prima para a preparação de carbóxi-metil-celulose insolúvel com propriedades absorventes. Nele são apresentados e discutidos os resultados dos experimentos em que polpas branqueadas etanol/água são empregadas para, numa etapa, preparar o produto com as características citadas através de sua carbóxi-metilação na presença de excesso de ácido mono-cloro-acético.

\section{Experimental}

Matéria-prima :

A fração correspondente à medula foi separada do bagaço, fornecido pela Usina Ipiranga de São Carlos, por peneiramento via úmida de suspensão de $200 \mathrm{~g}$ de matéria-prima em 4 litros de água. Nesta etapa, a suspensão contendo o bagaço integral foi inicialmente agitada por 1 hora a $70{ }^{\circ} \mathrm{C}$ (o que permitiu a extração de substâncias hidrossolúveis), resfriada à temperatura ambiente e então forçada através do conjunto de peneiras com o auxílio de ducha de água.

\section{Polpação etanol/água:}

Após secagem a $70{ }^{\circ} \mathrm{C}$ por 24 horas a medula foi submetida a um processo de polpação com mistura etanol/água (1:1/v:v) em reator de 2 litros observando a relação 1:30 (m/v) entre medula e etanol/água. Após a polpação por 1 hora a $190{ }^{\circ} \mathrm{C}$, a medula foi filtrada, extraída com etanol e depois com água quente $\left(90^{\circ} \mathrm{C}\right)$, lavada com água fria até a neutralidade e seca ao ar. A polpa obtida foi branqueada pelo processo clorito de sódio ${ }^{14}$, seguido de extração com solução aquosa

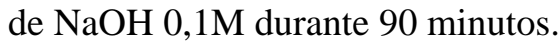

\section{Carbóxi-metilação das polpas ${ }^{12}$}

Em um experimento típico, a polpa branqueada moída, cerca de $8,5 \mathrm{~g}$, foi suspensa em $270 \mathrm{~mL}$ de isopropanol e vigorosamente agitada em reator de vidro. Foram adicionados $6,6 \mathrm{~g}$ de $\mathrm{NaOH}$ dissolvidos em $25 \mathrm{~mL}$ de água e a suspensão foi mantida sob agitação mecânica à temperatura ambiente durante 30 minutos. Em seguida, foram adicionados 10,21g de ácido mono-cloro-acético, a temperatura elevada para $80{ }^{\circ} \mathrm{C}$ e a reação foi deixada nessas condições durante 5 horas. Ao final desse período, o produto foi filtrado, abundantemente lavado com metanol e seco ao ar (amostra A). Mais sete amostras foram preparadas, variando-se o tempo de reação entre $3 \mathrm{e}$ 6 horas e a concentração de ácido mono-cloro-acético entre $0,54 \mathrm{M}$ e $1,0 \mathrm{M}$.

\section{Caracterizações:}

Polpas branqueadas foram caracterizadas quanto ao grau de umidade e teores de cinzas, lignina e holocelulose através de metodologia padrão ${ }^{14,15}$. O 
grau de polimerização foi determinado por medidas de viscosidade de soluções de polpa branqueada em cupra-etileno-diamina segundo norma padrão ${ }^{16}$.

\section{Solubilidade e Propriedades Absorventes}

Solubilidades em água e em solução aquosa 2,5 x $10^{-4} \mathrm{M}$ de $\mathrm{NaOH}$ foram determinadas após embebição por 12 horas, filtração, lavagem com metanol e pesagem do material insolúvel.

Capacidades de retenção de água (CRA) e de solução aquosa de $\mathrm{NaCl} 1 \%$ (CRS) foram determinadas através de metodologia semelhante àquela empregada para a caracterização de produtos absorventes obtidos a partir da carbóxi-metilação de polpas de madeira ${ }^{12}$. Após a embebição da amostra, cerca de $0,3 \mathrm{~g}$, em $100 \mathrm{~mL}$ de água (ou solução salina) durante 16 horas, filtração e centrifugação a $2500 \mathrm{rpm}$ durante 20 minutos, as massas do material úmido $\left(\mathrm{m}_{\mathrm{u}}\right)$ e seco em estufa a $100{ }^{\circ} \mathrm{C}\left(\mathrm{m}_{\mathrm{s}}\right)$ foram determinadas. Os valores de capacidades de retenção de solução aquosa de $\mathrm{NaCl} 1 \%$ (CRS) foram corrigidos devido à contribuição do sal à massa de material seco $\left(\mathrm{m}_{\mathrm{s}}\right)$. As expressões abaixo foram empregadas para os cálculos de CRA e CRS em termos percentuais.

$$
\text { (\%) } \mathrm{CRA}=\left(\mathrm{m}_{\mathrm{u}}-\mathrm{m}_{\mathrm{s}} / \mathrm{m}_{\mathrm{s}}\right) 100
$$

$(\%) \mathrm{CRS}=\left[\left(\mathrm{m}_{\mathrm{u}}-0,99 \mathrm{~m}_{\mathrm{s}}\right) / 0,99 \mathrm{~m}_{\mathrm{s}}\right] 100$

\section{Grau de Substituição}

Graus de substituição (DS) dos produtos carbóximetilados foram determinados por espectroscopia de ressonância magnética nuclear do próton (espectrômetro Bruker 200) de amostras hidrolisadas em meio $\mathrm{D}_{2} \mathrm{SO}_{4} / \mathrm{D}_{2} \mathrm{O}^{17}$ e por dosagem de sódio via titulação das cinzas de amostras incineradas ${ }^{18}$.

Nas determinações de DS através de espectroscopia de ressonância magnética nuclear, a amostra de carbóxi-metil-celulose, cerca de $50 \mathrm{mg}$, foi suspensa em $1 \mathrm{~mL}$ de mistura $\mathrm{D}_{2} \mathrm{O} / \mathrm{D}_{2} \mathrm{SO}_{4}(1: 1 / \mathrm{v}: \mathrm{v})$ e a suspensão aquecida a $90{ }^{\circ} \mathrm{C}$ por 90 - 120 minutos. A obtenção de solução límpida, ligeiramente amarelada, foi tomada como evidência de que a hidrólise procedeu sem ocorrência de degradação da amostra através de reações colaterais. Ácido acético foi adicionado como padrão de referência interna, e uma alíquota, cerca de $0,4 \mathrm{~mL}$ da solução, foi transferida para o tubo de ressonância para a varredura do espectro. As atribuições dos sinais observados nos espectros foram feitas segundo descrito na literatu- $\mathrm{ra}^{17}$ e os valores de graus de substituição (DS) calculados através da expressão abaixo.

$$
\mathrm{DS}=(\mathrm{a} / 2) /(\mathrm{c} / 6)
$$

Nessa expressão, a e c correspondem às áreas dos sinais atribuídos aos 2 átomos de hidrogênio dos metilenos dos grupos carbóxi-metila e aos 6 átomos de hidrogênio ligados aos átomos de carbono $2,3,4,5$ e 6 das unidades anidroglicopiranose, respectivamente.

Nas dosagens de sódio empregadas para a determinação de DS, a amostra seca, cerca de $0,5 \mathrm{~g}$, foi incinerada em cadinho de porcelana na chama do bico de bunsen e, em seguida, calcinada em mufla durante 4 horas a $600{ }^{\circ} \mathrm{C}$. As cinzas secas foram dissolvidas em água e a solução resultante titulada com solução aquosa padronizada de ácido sulfúrico $0,1 \mathrm{M}$. Atingido o ponto de equivalência, detectado pela presença de vermelho de metila como indicador, a solução foi aquecida para a eliminação de $\mathrm{CO}_{2} \mathrm{e}$ mais ácido foi adicionado até que um novo ponto final fosse observado. Os valores de DS foram calculados a partir da expressão

$$
\mathrm{DS}=(0,162 \mathrm{~B}) /(1-0,08 \mathrm{~B})
$$

sendo $\mathrm{B}$ o número de miliequivalentes de sódio por grama da amostra de carbóxi-metil-celulose dosada.

Análises Térmicas e Microscopia Eletrônica de Varredura

Análises calorimétricas diferenciais de varredura foram realizadas com cerca de $10 \mathrm{mg}$ de amostra em equipamento Netzsch DSC 200, operando entre $-20{ }^{\circ} \mathrm{Ce} 100{ }^{\circ} \mathrm{C}$ e taxa de aquecimento de $10{ }^{\circ} \mathrm{C} / \mathrm{min}$.

Micrografias foram obtidas em Digital Scanning Microscope após secagem das amostras por 24 horas em estufa a vácuo, a cerca de $50{ }^{\circ} \mathrm{C}$, e após recobrimento com ouro em Sputter Coater por 7 minutos.

\section{Resultados e Discussão}

\section{Obtenção e Caracterização de Polpas Etanol/Água de Medula}

O processo etanol / água de polpação foi aplicado à medula nas condições descritas como sendo as melhores, em termos de rendimento e eficiência de 
deslignificação, por um estudo cinético realizado com fibras de bagaço ${ }^{19}$. Em vista da maior capacidade de absorção de líquidos da medula, foi introduzida uma única modificação no procedimento de polpação descrito para as fibras verdadeiras e que consistiu na utilização de maior volume de etanol/ água.

A aplicação da polpação etanol / água à medula resultou em rendimento da ordem de $45 \%$, o que está de acordo com resultados da literatura relativos à polpação de fibras de bagaço ${ }^{20}$. Em ambos os casos, os rendimentos são inferiores aos obtidos quando processos industriais, como o Soda / Antraquinona, são aplicados provavelmente devido à maior ocorrência de degradação da fração de polissacarídeos, inclusive celulose, na polpação etanol / água.

De fato, no processo etanol/água, bem como em outros processos organossolve em que não são utilizados catalisadores, o meio reacional torna-se ácido devido à liberação de ácido acético proveniente da hidrólise de grupos acetila de polioses presentes na fibra vegetal. Em vista da susceptibilidade de polissacarídeos à hidrólise em meio ácido, parece razoável supor que, na polpação etanol/água, esse processo seja o responsável pela queda de rendimento.

A polpa não-branqueada apresentou teor de lignina em torno de $3,5 \%$ e o rendimento da etapa de branqueamento com clorito de sódio foi de cerca de $75 \%$. Rendimentos dos processos de polpação e de branqueamento e características das polpas etanol / água de medula são apresentados na Tabela 1.

Tabela 1. Rendimentos de polpação e branqueamento e características das polpas etanol/água de medula de bagaço de cana de açúcar.

\begin{tabular}{ccc}
$\begin{array}{c}\text { Teores } \\
\text { Percentuais }\end{array}$ & $\begin{array}{c}\text { Polpa não- } \\
\text { branqueada }\end{array} \quad$ Polpa branqueada \\
\hline
\end{tabular}

\begin{tabular}{|c|c|c|}
\hline Rendimento & 46 & 75 \\
\hline $\begin{array}{l}\text { Lignina Klason } \\
\text { Insolúvel }\end{array}$ & 3,4 & - \\
\hline Número Kappa ${ }^{(a)}$ & $<15$ & - \\
\hline Holocelulose & - & $>80$ \\
\hline
\end{tabular}

O grau de polimerização da polpa branqueada foi calculado através da expressão proposta por Immerget, Shurtz e Mark, a partir da determinação de viscosidade intrínseca em solução de cupra-etilenodiamina $^{16}$. $\mathrm{O}$ valor da viscosidade intrínseca de solução $0,004 \mathrm{~g} / \mathrm{cm}^{3}$ de polpa foi de $412,5 \mathrm{~cm}^{3} / \mathrm{g}$ e o correspondente grau de polimerização, igual a 565 . Este valor é inferior ao de polpas etanol/água de fibras de bagaço, o que resulta do fato de as cadeias de celulose na medula apresentarem menor grau de polimerização.

\section{Características de Carbóxi-metil-celulose Absorvente Preparada de Polpa de Medula}

$\mathrm{Na}$ Tabela 2 são apresentados os dados relativos a solubilidade em água $\left(S_{\mathrm{W}}\right)$, capacidades de retenção de água (CRA) e de solução aquosa salina (CRS) e graus de substituição (DS) de polpas carbóximetiladas obtidas empregando diferentes concentrações de ácido mono-cloro-acético.

Como pode ser constatado dos dados da Tabela 2, os produtos obtidos pela carbóxi-metilação das polpas etanol/água de medula nas condições descritas são pouco solúveis em água. Isso se deve ao fato de a reação proceder por tempo suficiente em presença de excesso do agente eterificante neutralizado, monocloro-acetato de sódio, frente à concentração restante

Tabela 2. Solubilidade, grau de substituição e propriedades absorventes de polpas carbóxi-metiladas em função da concentração de ácido monocloro-acético, $\mathrm{ClAcOH}$, empregado em sua obtenção.

\begin{tabular}{|c|c|c|c|c|c|c|}
\hline Amostra & {$[\mathrm{ClAcOH}]^{(\mathrm{a})}$} & $\begin{array}{l}\mathrm{S}_{\mathrm{W}} \\
(\%)\end{array}$ & $\mathrm{DS}^{(\mathrm{b})}$ & $\mathrm{DS}^{(\mathrm{c})}$ & $\begin{array}{c}\text { CRA } \\
(\%)\end{array}$ & $\begin{array}{c}\text { CRS } \\
(\%)\end{array}$ \\
\hline A & 0,37 & 8,5 & 0,76 & 0,11 & 220,4 & 153,7 \\
\hline B & 0,54 & 37,8 & 0,82 & 0,17 & 249,6 & 174,4 \\
\hline $\mathrm{C}$ & 0,74 & 15,0 & 0,84 & 0,14 & 640,4 & 196,2 \\
\hline D & 0,90 & 11,6 & 0,96 & 0,12 & 662,6 & 202,9 \\
\hline $\mathrm{E}$ & 1,00 & 19,7 & - & 0,15 & 321,6 & 168,3 \\
\hline
\end{tabular}

a) Concentração (mol/L) de ácido mono-cloro-acético presente no início da reação;

b) valores determinados através de espectroscopia de ressonância magnética nuclear do próton ${ }^{17}$;

c) valores determinados através da dosagem de sódio nas cinzas das $\operatorname{amostras}^{18}$. 
de hidróxido de sódio ${ }^{12}$. Em todos os casos aqui relatados, a relação molar $\mathrm{ClAcO}^{(-)} \mathrm{Na}^{(+)} / \mathrm{NaOH}$ foi igual ou superior a 2, pois quando foi empregada uma relação menor, o produto obtido apresentou baixa capacidade de absorção de água e solubilidade superior a $75 \%{ }^{21}$. É necessário ressaltar, entretanto, que todas as amostras apresentaram valores de grau de substitutição (DS), determinados através de espectroscopia de ressonância magnética nuclear, comparáveis àqueles normalmente apresentados por produtos solúveis.

Com o objetivo de tentar esclarecer a relação entre o conteúdo de grupos carbóxi-metila e a solubilidade das amostras, dois procedimentos distintos foram adotados para as determinações de graus de substituição: $i)$ através de espectroscopia de ressonância magnética nuclear do próton ${ }^{17} \mathrm{e}$ ii) pela dosagem de sódio ${ }^{18}$ modificada pela exclusão da etapa de conversão das amostras à forma salina.

Nas determinações de DS de carbóxi-metilcelulose através de espectroscopia de ressonância magnética nuclear do próton, as amostras são completamente hidrolisadas em meio $\mathrm{D}_{2} \mathrm{SO}_{4} / \mathrm{D}_{2} \mathrm{O}$ a fim de evitar que a viscosidade do polímero provoque o alargamento dos sinais e dificulte a obtenção de espectros interpretáveis. A ocorrência de hidrólise completa é verificada através da relação entre as áreas dos sinais devidos ao próton ligado ao carbono $1 \mathrm{e}$ aos seis prótons ligados aos carbonos 2, 3, 4, 5 e 6 da unidade de anidroglicopiranose. O grau de substituição é determinado a partir da área dos sinais devidos aos prótons metilênicos dos grupos carbóximetila presentes nas unidades de anidroglicopiranose e os valores de DS determinados através desse procedimento são, na faixa de DS $<3,0$, sempre superiores àqueles obtidos pelo emprego de procedimentos de titulação ${ }^{18}$. Isso é atribuído ao fato de, no caso da determinação via espectroscopia de ressonância magnética nuclear, todas as unidades monoméricas serem levadas em consideração, enquanto que, no caso dos procedimentos de titulação, a conversão incompleta à forma ácida e a ocorrência de agregação levam à subestimação do valor de DS.

Assim, os valores de DS determinados através de espectroscopia de ressonância magnética nuclear correspondem, de fato, à melhor aproximação do número médio de grupos carbóxi-metila presentes por unidade de anidroglicose nas amostras de carbóximetil-celulose. Entretanto, os valores de graus de substituição determinados através da dosagem de sódio presente nas cinzas das amostras incineradas foram entre 5 e 8 vezes menores (Tabela 2), o que pode ser melhor compreendido na discussão a seguir.

Nas determinações de DS de carbóxi-metilcelulose através da dosagem de sódio nas cinzas da amostra incinerada o pressuposto básico é que exista uma relação estequiométrica equimolar entre grupos carboximetila negativamente carregados e contra-íons sódio. Para assegurar a observância dessa condição a amostra é convertida à forma salina por tratamento em suspensão aquosa alcalina, seca e então incinerada. Através desse procedimento, o $\mathrm{Na}_{2} \mathrm{O}$ formado na incineração da amostra é decomposto a $\mathrm{NaOH}$ em solução aquosa e este último é titulado com solução padronizada de ácido sulfúrico diluído. Os erros de pesagem, a presença de impurezas, a conversão incompleta da amostra à forma salina e perdas de massa por solubilização parcial são as principais fontes de imprecisão nas determinações de DS por dosagem de sódio.

Neste trabalho, a dosagem de sódio após incineração dos produtos não foi precedida de tratamento alcalino para conversão à forma salina. Desta forma, a dosagem realizada de fato reflete o número médio de grupos carbóxi-metila que possuem contra-íons sódio. Portanto, os baixos valores de DS determinados através deste procedimento devem ser atribuídos ao fato de poucos grupos carbóxi-metila se encontrarem presentes na forma de sal de sódio. Por outro lado, o procedimento que emprega ressonância magnética nuclear para adeterminação de DS não faz distinção entre grupos carbóxi-metila nas formas salina e protonada mas fornece valores mais precisos, independentemente do grau de pureza da amostra analisada, e permite avaliar, por comparação com os resultados obtidos através da técnica de cinzas, a fração correspondente a grupos carbóxi-metila na forma ácida.

Em vista desses resultados deve ser concluído que as amostras de carbóxi-metil-celulose obtidas nas condições descritas têm entre $80 \%$ e $90 \%$ dos grupos carbóxi-metila sob a forma protonada, e este é um dos fatores responsáveis pela baixa solubilidade apresentada pelos produtos. A amostra D apresentou solubilidade em meio aquoso alcalino cerca de três vezes superior àquela exibida em água pura, o que também deve ser tomado como uma forte evidência do cárater ácido do produto ${ }^{21}$. Entretanto, a estrutura da rede polimérica não foi totalmente destruída pois a completa solubilização da amostra não foi 
conseguida mesmo com o prolongamento do tempo de embebição no meio alcalino.

Quanto aos valores de DS, pode ser verificado na Tabela 2 que, como esperado, o conteúdo de grupos carbóxi-metila é maior nas amostras obtidas em presença de maior excesso de ácido mono-cloroacético. No caso da amostra $\mathrm{E}$, não foi possível determinar o valor de DS através de espectroscopia de ressonância magnética nuclear devido à ocorrência de severa degradação da amostra durante a hidrólise, o que foi evidenciado pela obtenção de uma suspensão viscosa e escura.

O comportamento absorvente das amostras de carbóxi-metil-celulose em função da concentração de ácido mono-cloro-acético empregado em sua obtenção é melhor avaliado através das curvas na Figura 1.

Pela Figura 1, pode ser constatado que os produtos de carbóxi-metilação das polpas etano/água de bagaço possuem capacidade de retenção de água superior àquela apresentada pela matéria-prima empregada em sua obtenção, e que essa superioridade é mais acentuada à medida que aumenta a concentração de ácido mono-cloro-acético empregado na reação de carbóxi-metilação. Portanto, o aumento observado da capacidade de retenção de água também acompanha o aumento dos respectivos valores de grau de substituição (DS) e deve ser atribuído à presença de grupos ionizáveis no interior da rede polimérica. Assim, apesar de substancialmente insolúveis, os produtos obtidos contêm grupos que se caracterizam por apresentarem grande afinidade por água.

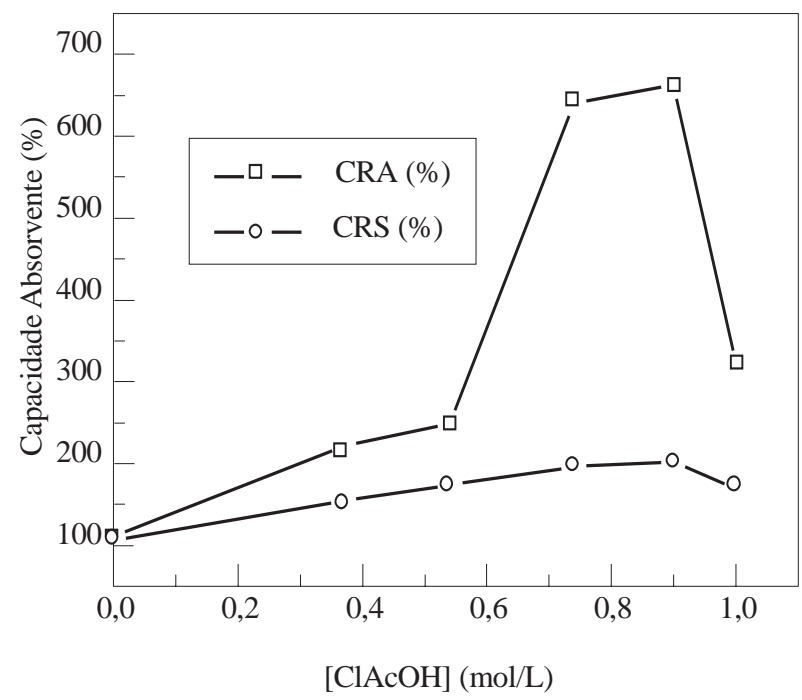

Figura 1. Capacidades de retenção de água (CRA) e de solução aquosa salina (CRS) de carbóxi-metil-celulose em função da concentração de ácido mono-cloro-acético empregado em sua obtenção.
De fato, a presença de grupos carbóxi-metila na forma ácida é, em grande parte, responsável pela pouca solubilidade dos produtos, e é sua ionização parcial que confere propriedades absorventes superiores às da polpa de partida. Isso se deve à pressão osmótica que se desenvolve no interior da rede polimérica pela dissociação de íons $\mathrm{H}^{+}$. Tal conclusão é respaldada pela ocorrência do efeito polieletrolítico, constatável pela redução das capacidades absorventes dos produtos quando $\mathrm{NaCl}$ está presente na água de embebição (Figura 1). No caso de polieletrólitos solúveis, a blindagem das interações repulsivas entre as cargas sobre as cadeias, devida aos íons $\mathrm{Na}^{+}$adicionados à solução, se manifesta pela diminuição da viscosidade com o aumento da concentração de $\mathrm{sal}^{22}$. Nos produtos deste trabalho, o efeito polieletrolítico se expressa pela contração da rede polimérica e, conseqüentemente, pela menor capacidade de retenção da solução aquosa.

A diminuição da capacidade de retenção de líquido pelas polpas carbóxi-metiladas, observada em solução aquosa de $\mathrm{NaCl}$ a $1 \%$, deve portanto ser atribuída ao efeito polieletrolítico. Tal efeito não se manifesta quando a polpa não-carbóxi-metilada é embebida na solução salina já que esta não contém grupos iônicos ao longo das cadeias de celulose. Quanto à intensidade do efeito de redução da capacidade absorvente manifestado pelas amostras carbóxi-metiladas, dois grupos de comportamentos distintos podem ser identificados. Ao serem embebidas em solução aquosa salina, as amostras A e B apresentaram uma redução de cerca de $30 \%$ em suas capacidades absorventes enquanto que as amostras $\mathrm{C}$ e D exibiram uma diminuição mais acentuada, cerca de $70 \%$, quando submetidas ao mesmo tratamento. $\mathrm{A}$ amostra $\mathrm{E}$ manifestou um efeito intermediário, quase $50 \%$ de redução na capacidade absorvente, nas mesmas condições.

Caso o efeito observado fosse atribuível tão somente ao conteúdo de grupos carbóxi-metila sobre as cadeias celulósicas, seria esperado que as amostras possuidoras dos maiores valores de grau de substituição (DS) apresentassem reduções mais drásticas nas capacidades de retenção de solução aquosa salina. Essa tendência foi, de fato, observada (Tabela 2). Porém, diferenças muito pequenas nos valores de grau de substituição (DS) resultaram em variações muito grandes nas respectivas reduções das capacidades de retenção de solução aquosa salina.

Considerando a capacidade de retenção de água, 
Tabela 3. Solubilidade, grau de substituição e propriedades absorventes de polpas carboxi-metiladas em função do tempo de reação empregado em sua obtenção ${ }^{(a)}$.

\begin{tabular}{|c|c|c|c|c|c|c|}
\hline Amostra & $\begin{array}{l}\text { Tempo } \\
\text { (h) }\end{array}$ & $\begin{array}{l}\mathrm{S}_{\mathrm{W}} \\
(\%)\end{array}$ & $\mathrm{DS}^{(\mathrm{b})}$ & $\mathrm{DS}^{(\mathrm{c})}$ & $\begin{array}{c}\text { CRA } \\
(\%)\end{array}$ & $\begin{array}{c}\text { CRS } \\
(\%)\end{array}$ \\
\hline $\mathrm{F}$ & 3 & 25,4 & 0,69 & 0,16 & 393,2 & 163,0 \\
\hline G & 4 & 1,7 & 0,76 & 0,10 & 841,5 & 239,4 \\
\hline $\mathrm{D}$ & 5 & 11,6 & 0,96 & 0,12 & 662,6 & 202,9 \\
\hline $\mathrm{H}$ & 6 & 10,9 & 0,72 & 0,11 & 442,4 & 172,0 \\
\hline
\end{tabular}

a) As condições empregadas nas reações de obtenção desse produtos são aquelas descritas para a amostra D;

b) Valores determinados através de espectroscopia de ressonância magnética nuclear do próton ${ }^{17}$;

c) Valores determinados através da dosagem de sódio nas cinzas das $\operatorname{amostras}^{18}$

a amostra D (Tabela 2) foi aquela que apresentou as melhores propriedades. Com o objetivo de avaliar o efeito do tempo de reação sobre as características da carbóxi-metil-celulose obtida, foram realizadas mais três preparações em condições idênticas àquelas empregadas para obtenção da amostra $\mathrm{D}$, a menos do tempo, que variou no intervalo de 3 a 6 horas. As características dos produtos obtidos nessas condições são apresentadas na Tabela 3.

Por esses dados pode-se constatar que um mínimo de solubilidade é atingido quando a reação é interrompida após 4 horas a $80{ }^{\circ} \mathrm{C}$, em presença de 0,90 mol/L de ácido mono-cloro-acético no meio reacional. Esse produto e também aqueles obtidos a diferentes tempos de reação apresentam valores de DS comparáveis àqueles de produtos solúveis. Também nesses casos se aplicam as observações relativas às técnicas de determinação de DS e a constatação de que se trata de amostras de carboxi-metilcelulose predominantemente obtidas em forma ácida.

Quanto às características absorventes, o perfil de sua variação em função do tempo de reação é melhor avaliado na Figura 2.

Também com relação ao parâmetro tempo de reação, pode ser observada na Figura 2 a ocorrência de um valor máximo para a capacidade de retenção de água (CRA), como já havia sido constatado com relação à concentração de ácido mono-cloro-acético

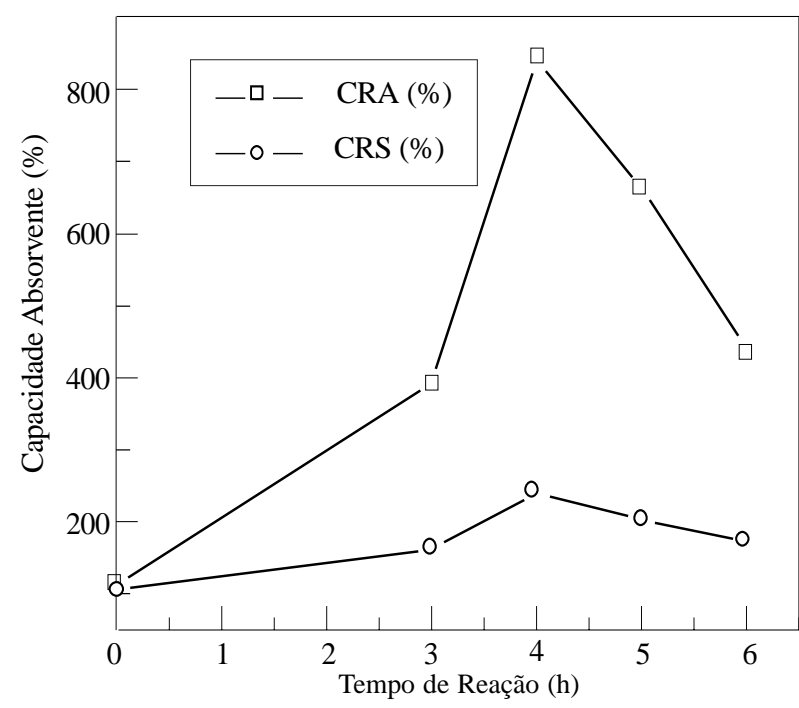

Figura 2. Capacidades de retenção de água (CRA) e de solução aquosa salina (CRS) de carbóxi-metil-celulose em função do tempo de reação empregado em sua obtenção.

empregado na carbóxi-metilação das polpas. Tempos de reação maiores ou menores resultaram em produtos mais solúveis e com características absorventes inferiores àquelas da amostra obtida através de carbóxi-metilação durante quatro horas.

Quanto às variações nas capacidades de retenção de água e de solução aquosa salina, pode ser verificado que todos os produtos apresentam o efeito polieletrolítico, mas novamente pode ser constatado que não há uma relação direta entre o valor de DS e a redução na capacidade absorvente em solução aquosa salina. Por outro lado, diferentemente do que foi observado quando a concentração de ácido monocloro-acético foi variada, no caso das amostras obtidas em diferentes tempos de carbóxi-metilação pode ser observado um comportamento mais uniforme. Assim, essas amostras apresentam redução da capacidade absorvente em torno de $60 \%$ a $70 \%$ quando a água de embebição contém $\mathrm{NaCl}$ enquanto os respectivos graus de substituição (DS) variam no intervalo $0,69<\mathrm{DS}<0,96$.

Deve ser ressaltado que não foi constatada uma relação biunívoca entre os valores de DS e as propriedades absorventes de água e de solução salina pelos produtos deste trabalho. Assim, por exemplo, as amostras A e F apresentam valores de DS $=0,76$, porém diferem muito quanto às respectivas capacidades de retenção de água e de solução salina. Além disso, essas amostras apresentam comportamentos quantitativamente distintos quanto às reduções nas suas capacidades absorventes devido à presença de $\mathrm{NaCl}$ na água de embebição. Por outro 
lado, as amostras C e D apresentam características semelhantes quanto a comportamentos absorventes e sensibilidades à presença de sal na água de embebição mas exibem valores bem distintos de DS.

Esses resultados sugerem que outros fatores devem ser também considerados para compreeender os comportamentos observados, dentre eles a resposta elástica da rede e o grau de afinidade entre as cadeias poliméricas. O primeiro fator está associado ao grau de intercruzamento da rede polimérica, e o segundo depende das interações polímero / polímero e polímero / solvente ${ }^{23}$. A avaliação da importância relativa de ambos os fatores deve ser feita através da caracterização mais detalhada da estrutura dos produtos e de seus comportamentos em relação à solubilidade em função do pH e à absorção de soluções aquosas de diferentes forças iônicas.

\section{Características morfológicas}

As características morfológicas da polpa etanol/água de medula e de um dos produtos de carbóxi-metilação com boas propriedades absorventes, a amostra D, foram determinadas através de microscopia eletrônica de varredura (Figura 3).

Para a realização dessas análises, ambos os materiais foram primeiramente condicionados em água durante 16 horas, de modo que as fotomicrografias apresentadas correspondem a amostras completamente expandidas. Pela comparação dessas fotomicrografias pode ser observado que a amostra carbóxi-metilada apresenta muito

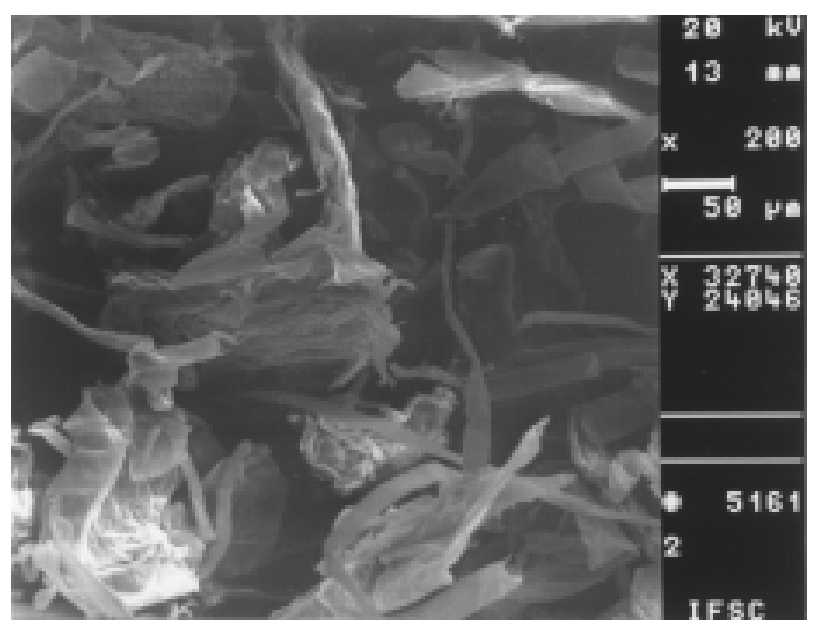

(a) menos regiões vazias e que corresponde, aparentemente, a um material de natureza mais homogênea que a polpa não-carbóxi-metilada. O fato de a amostra $\mathrm{D}$ apresentar menos espaços vazios é indicativo que este material se encontra mais expandido e, portanto, pode conter mais água aprisionada em sua estrutura. A aparência heterogênea da polpa nãocarbóxi-metilada deve ser atribuída ao fato de este material conter algumas estruturas celulares parcialmente preservadas, o que certamente não ocorre no caso da amostra $\mathrm{D}$ devido à modificação química que sofreu através da reação de carbóxi-metilação. De fato, a estrutura da polpa não-branqueada, examinada com aumento de 10.000 vezes, revela a existência de regiões que preservam a natureza fibrosa do material e a ocorrência de empacotamento com formação de fibrilas altamente cristalinas ${ }^{21}$. Nos casos da polpa branqueada e da amostra $\mathrm{D}$, essas estruturas não foram observadas mas constatou-se a natureza amorfa deste último material bem como alguma heterogeneidade, observada pela presença de estruturas granulares aparentes já no aumento de 200 vezes.

\section{Calorimetria Diferencial de Varredura}

Materiais absorventes contêm dois tipos distintos de água que interagem com o hidrogel ${ }^{24}:$ i) água associada à rede macromolecular e ii) água que envolve a rede polimérica. $\mathrm{O}$ primeiro tipo pode ser subdividido a partir da consideração de que parte do líquido se associa fortemente à rede e faz parte da

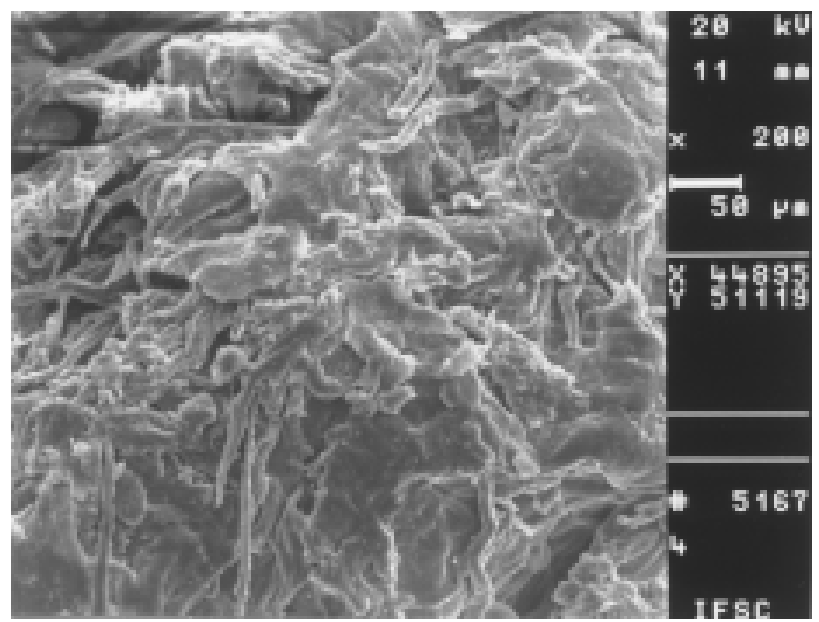

(b)

Figura 3. Fotomicrografias dos materiais expandidos em água: a) polpa branqueada etanol / água de medula de bagaço de cana de açúcar; b) amostra carbóxi-metilada D. (Aumento de 200 vezes). 
estrutura do hidrogel enquanto a outra fração interage mais fracamente com as cadeias poliméricas. A água estrutural do hidrogel é denominada "água ligada" e se associa às cadeias poliméricas através de pontes de hidrogênio e/ou interações dipolo-dipolo. A fração de moléculas de água que interage mais fracamente com o polímero, localizada nas proximidades de grupos hidrofóbicos da macromolécula, é denominada "água intersticial”. A denominação "água livre" é empregada para designar a água que não participa da estrutura do hidrogel mas que envolve a rede polimérica que o constitui. Em função dos diferentes graus de associação que mantêm com as cadeias poliméricas, esses diferentes tipos de água são distintos do ponto de vista de suas propriedades físicas, tais como ponto de fusão e viscosidade. Se o hidrogel é resfriado abaixo de $0{ }^{\circ} \mathrm{C}$, a fração correspondente à "água livre", a exemplo do que acontece com a água pura, passa para o estado sólido. Em decorrência do grau de interações que estabelecem com a rede polimérica, as frações correspondentes à "água ligada" e à "água intersticial" apresentam comportamento diferente daquele da "água livre". No primeiro caso, não ocorre mudança de estado enquanto que, no segundo, a solidificação ocorre abaixo de $0{ }^{\circ} \mathrm{C}$. A distinção entre os diferentes tipos de água acima definidos pode ser realizada através de calorimetria diferencial de varredura ${ }^{25}$.

$\mathrm{Na}$ Figura 4 são mostrados o termograma resultante da análise por calorimetria diferencial de varredura da amostra de polpa branqueada etanol/água de medula e o de um de seus produtos carbóximetilados (amostra G).

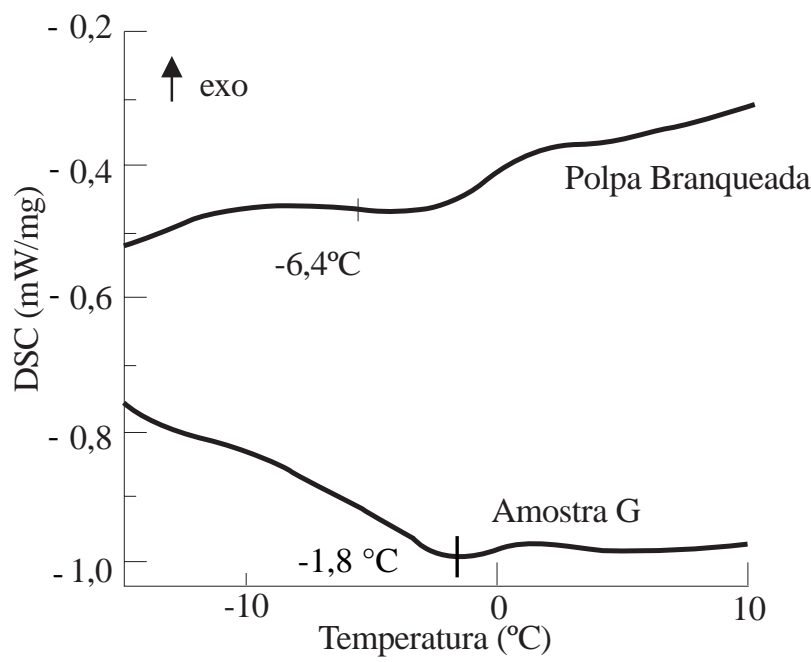

Figura 4. Termogramas resultantes da análise por calorimetria diferencial de varredura de: a) polpa branqueada etanol/água de medula e b) amostra carbóxi-metilada G.
Ambos os materiais se encontram no estado expandido de hidrogel pois foram inicialmente embebidos em água por 16 horas e o excesso de água foi excluído por filtração. Portanto, as transições endotérmicas observadas em $-6,4{ }^{\circ} \mathrm{C} \mathrm{e}-1,8{ }^{\circ} \mathrm{C}$ para a polpa e a amostra $\mathrm{G}$, respectivamente, devem ser atribuídas à fusão da água. Embora a resolução dos termogramas não permita a identificação dos diferentes tipos de água definidos acima, a comparação do sistema estudado com outros géis hidrofílicos indica que as transições observadas estão relacionadas ao processo de fusão de a "água intersticial" ${ }^{26}$. Neste caso, os diferentes pontos de fusão podem ser atribuídos ao fato de a "água intersticial" estar confinada em volumes diferentes quando as redes poliméricas da polpa e da amostra $G$ são consideradas. Assim, a rede polimérica do hidrogel formado pela interação da amostra $\mathrm{G}$ com água encontra-se mais expandida devido à presença de cargas originadas da ionização dos grupos carbóxi-metila. No caso da polpa, a inexistência de repulsões eletrostáticas resulta em menor capacidade de retenção de água, menor volume no estado expandido e, consequentemente, a "água intersticial" se encontra mais constrita, o que provoca um abaixamento mais importante no seu ponto de fusão.

\section{Conclusões}

Considerando o conjunto de resultados apresentados, o produto com melhores características, visando a aplicação como material absorvente, foi obtido quando a polpa branqueada etanol/água de medula foi submetida à reação de carbóxi-metilação a $80^{\circ} \mathrm{C}$, durante 4 horas, na presença de ácido mono-cloroacético na concentração $0,90 \mathrm{M}$. Este produto, correspondente à amostra $\mathrm{G}$, apresentou solubilidade muita baixa $\left(S_{\mathrm{W}}=1,7 \%\right)$ e capacidade de retenção de água quase oito vezes superior à da medula não-carbóximetilada. Em vista de se tratar de um polieletrólito, sua capacidade absorvente é bastante reduzida, quando embebido em soluções aquosas salinas. Sua aplicação na confecção de papel absorvente é sugerida, pois, além de apresentar boa capacidade de absorção de água, exibe alvura compatível com essa finalidade em função de ser obtido a partir de polpa branqueada e de não ser submetido a processamento térmico, o que costuma resultar em produtos mais ou menos escurecidos em função da severidade do tratamento. Entretanto, as propriedades mecânicas do papel resultante devem 
ser avaliadas, pois é conhecido que a medula empobrece suas características de resistência ao rasgo e à ruptura. No caso das polpas carbóxi-metiladas deste trabalho, tal efeito deletério pode não ocorrer dado que a morfologia da medula deve ser modificada em razão das alterações químicas introduzidas em sua estrutura. A microscopia eletrônica de varredura da polpa etanol/água de medula e a de um dos produtos obtidos após carbóxi-metilação indicam que, de fato, parte da estrutura morfológica da medula é destruída pela reação de carbóxi-metilação. Os resultados obtidos sugerem ainda que produtos com características superiores de retenção de líquidos podem ser preparados a partir de medula submetida a processos de polpação que resultem na maior preservação das cadeias celulósicas no que diz respeito ao grau de polimerização. Trabalho nesse sentido, empregando polpas Soda / Antraquinona de medula, se encontra em andamento em nossos laboratórios.

\section{Agradecimentos}

Os autores agradecem à CAPES a bolsa de Mestrado concedida a Cibele M.F.Martinez durante a realização deste trabalho.

\section{Referências Bibliográficas}

1. Rowell,R.; Workshop Internacional "Aplicação de fibras vegetais na indústria automobilística"; CNPDIA / EMBRAPA (1996).

2. Avaliação da evolução da safra 94/95. Posição em 28/02/95. AIAA - SIAESP - SIFAESP. São Paulo (1995).

3. Paturau, J.M. - "By-Products of Sugar Cane Bagasse"; Elsevier Publ. Comp.- Amsterdam/ London/New York, Part II (1969).

4. Campana Filho,S.P.; Curvelo,A.A.S.; Caraschi J. Braz.Assoc.Advanc. Sci., 45(1), 42-45 (1993).

5. Curvelo A.A.S.; Pereira, R.E.; Campana Filho,S.P.; Gandini,A.- submetido a Cellulose.

6. Mattoso, L.H.C.; Zucolloto,V.; Paterno,L.G.; Griethuijsen,R.; Ferreira,M.; Oliveira Jr.,O.N.; Campana Filho,S.P. - Synthetic Metals 71, 2037-2038(1995).

7. Engelhardt,F.; Ebert,G.; Funk,R. - Advanced Materials 4(3), 227-230(1992).

8. Anberger,U.; Oppermann,W. - Polymer 31, 18541858(1990).
9. Nissan,A.H.; Hunger,G.K.; Sternstein,S.S. "Encyclopedia of Polymer Science and Technology"; vol.3,190; Ed.H.F.Mark, Interscience, New York (1965).

10. Oppermann,W.; Rose,S.; Rehage,G. - Br.Polym.J. 17, 175 (1985).

11.Flory,P.J. - "Principles of Polymer Chemistry", Cornell University Press, Ithaca, New york (1953).

12. U.S..Patent 1372256 (1974).

13. U.S.Patent 4650716 (1987).

14. ABTCP - Normas da Associação Brasileira Técnica de Papel e Celulose. São Paulo - Brasil.

15. TAPPI STANDARDS - Testing Procedures of Technical Association of the Pulp and Paper Industry. Atlanta / Estados Unidos da América do Norte.

16. SCAN - C15:62 - Scandinavian Pulp, Paper and Board - Viscosity of Cellulose in Cupric ethylenediamine solution (CED) (1962).

17. Ho,F.F.; Klosiewicz,D.W. - Anal.Chem. 52, 913916(1980).

18. Wilson,K - Svensk Papper. 20, 714-715(1960).

19. Curvelo,A.A.S.; Pereira,R. - The $8^{\text {th }}$ International Symposium on Wood and Pulping Chemistry, Proceedings Vol.II, 473; Finland (1995).

20. Curvelo,A.A.S.; Caraschi,J.C.; Campana Filho, Polímeros, Ciência e Tecnologia jul/set, 24-29 (1996).

21. Martinez,C.M.F., "Obtenção e Caracterização de Materiais Absorventes através de Carboximetilação de Polpa de Etanol/Água de Medula de Bagaço de Cana-de-Acúcar", Dissertação de Mestrado apresentada ao IQSC/USP (1996).

22. Rice,S.A.; Nagasawa,M. - "Polyelectrolyte Solutions"; Academic Press, London/New York (1961).

23. Tanaka,T. - Scientific American 244, 110 125(1981).

24. Khare,A.R.; Peppas,N.A. - Polymer 34, 4736 4739 (1993).

25. Bershtein,V.A.; Egorov,V.M. - "Diferential Scanning Calorimetry of Polymers", p.225226 - Ed. by Ellis Horwood Limited (1994).

26. Seo,T.; Iijima,T. - "Biotechnology and Polymers”p. 218 - 220 - Ed. by C.G.Gebelein - Plenum Press (1991). 